\title{
Congenital epulis of the jaw: a series of five cases and review of literature
}

\author{
A. Marlijn Küpers · Peter Andriessen · Muriel J. P. van Kempen · \\ Ignaz G. H. van der Tol · Jacques A. Baart · Antoine G. Dumans • \\ Isaäc van der Waal
}

Accepted: 25 November 2008/Published online: 12 December 2008 (C) Springer-Verlag 2008

\begin{abstract}
This article describes five cases of congenital epulis, a rare and benign swelling in the mouth of a newborn, which is not widely known. We present five cases: four cases presented as single pedunculated nodules of the gingiva and in one case two nodules were present. Of all, $50 \%$ were located at the maxilla. Excision was performed in four of the five cases and in one case, spontaneous regression was awaited. No recurrence was reported. The characteristic features of congenital epulis are a pedunculated, flesh-pink coloured tumour with a predominant occurrence on the anterior maxillary alveolar ridge in a female newborn. Although the aetiology is unknown, most authors suggest a mesenchymal, rather than an
\end{abstract}

A. M. Küpers · P. Andriessen ( $)$

Neonatal Intensive Care Unit, Máxima Medical Centre,

PO Box 7777, 5500 MB Veldhoven, The Netherlands

e-mail: p.andriessen@mmc.nl

A. M. Küpers

e-mail: marlijnkupers@hotmail.com

M. J. P. van Kempen

Department of Otolaryngology, St Anna Hospital,

PO Box 90, 5660 AB Geldrop, The Netherlands

I. G. H. van der Tol

Department of Oral and Maxillofacial Surgery,

Alkmaar Medical Centre, PO Box 501,

1800 AM Alkmaar, The Netherlands

J. A. Baart · I. van der Waal

Department of Oral and Maxillofacial Surgery/Oral Pathology,

VU Medical Centre/ACTA, PO Box 7057,

1007 MB Amsterdam, The Netherlands

\section{A. G. Dumans}

Department of Oral and Maxillofacial Surgery,

Erasmus MC-Sophia Children's Hospital,

PO Box 2060, 3000 CB Rotterdam, The Netherlands odontogenic, origin. Endogenous hormonal factors might influence growth prenatally. Histological findings include granular cells with eosinophilic cytoplasm and small, eccentric nuclei. Despite the fact that the lesion can be a striking sight, spontaneous regression is possible and can be awaited. Indications for non-radical excision under local anaesthesia are severe upper airway obstruction and interference with feeding technique. In conclusion, we provide clinical and histological information about congenital epulis, so that this entity will be more easily recognised and relevant information given to parents.

Keywords Oral pathology · Oral surgery · Congenital epulis · Gingival neoplasm · Infant

\section{Introduction}

A congenital epulis is a rare benign tumour of the jaw present at birth and is also known as congenital gingival granular cell tumour or Neumann's tumour $[4,11]$. The Greek word "epulis" means "swelling of the gingiva" [4]. It occurs usually as a solitary, somewhat pedunculated firm, elastic tumour on the gingival mucosa of the anterior alveolar ridge of the maxilla or mandible. However, it has also been described on the tongue [7, 11]. The tumour is more common in female newborns (10:1) with a Caucasian predisposition $[5-8,11,16]$. Large lesions may interfere with respiration, feeding or adequate closure of the mouth $[6,11]$.

Since the first case described by Neumann in 1871, there are several cases reported in the pathological, odontological and otolaryngological literature $[9,11,16]$. The clinical presentation of congenital tumours can be impressive and distressing due to their size and aggressive appearance. Our 
purpose is to let paediatricians and paediatric surgeons get acquainted with this congenital tumour, so that an early, correct diagnosis and adequate information may be given to parents and healthcare professionals involved $[8,9]$. We report a series of five cases with typical presentation, treatment and histopathology.

\section{Series of five cases}

Case 1 is a female term newborn. After birth, a pedunculated, solid nodule of the gingiva of the right maxilla was seen, with a diameter of approximately $6 \mathrm{~mm}$. The tentative diagnosis was congenital epulis. Inadequate mouth closure during feeding resulted in aerophagy and was the indication for intervention. Under local anaesthesia, the mass was excised at the age of 5 weeks. At histopathological examination, regular nuclei in a granular cytoplasm were seen. The lesion was negative for S100 protein antigen and periodic acid-Schiff staining (PAS). These findings confirmed the diagnosis of congenital epulis. The postoperative course was uneventful and no further follow-up was necessary 1 month after surgery.

Case 2 is a female term newborn who presented with two solid swellings; one at the mandible measuring $7 \mathrm{~mm}$ in diameter and one located at the maxilla measuring $10 \mathrm{~mm}$ (Fig. 1). Both masses interfered with adequate bottle feeding. The patient underwent surgery at the age of 6 weeks, after which the feeding returned to normal. Histopathological findings showed a dense proliferation of rather monomorphic cells with granular cytoplasm and multiple small vessels in between (Fig. 2). S100 staining was negative. This was consistent with congenital epulis. No follow-up was needed.

Case 3 is a female term newborn showing a small mass at the alveolar ridge of the mandible, approximately $10 \mathrm{~mm}$ in diameter. The differential diagnosis included a congenital epulis or a fibroma. At the age of 1 month, the mass was excised under general anaesthesia without postoperative complications. Histopathology confirmed the diagnosis of a congenital epulis, showing a granular, eosinophilic cytoplasm with normal nuclei, a rich vascularisation and a lymphocytic infiltrate. Follow-up after a few weeks revealed no recurrence or late complications.

Case 4 is a female term newborn, who presented with a solid mass of approximately $10 \mathrm{~mm}$ in diameter, located at the superior alveolar ridge on the left paramedian side. Since the mass interfered with feeding, it was removed surgically 2 days after birth. Histopathology showed proliferative cells with granular, eosinophilic cytoplasm and central small, round nuclei with rich vascularisation in between. Immunohistochemically, S100 protein staining was negative. These findings confirm the diagnosis of

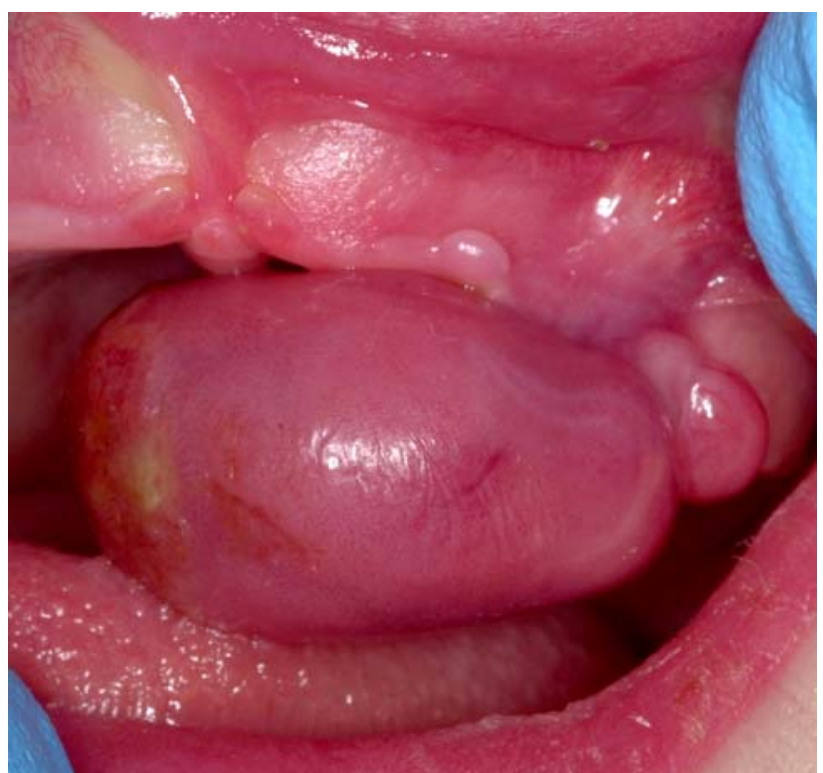

Fig. 1 Case 2, obstructive lesion on the left maxilla. (With permission of the parents)

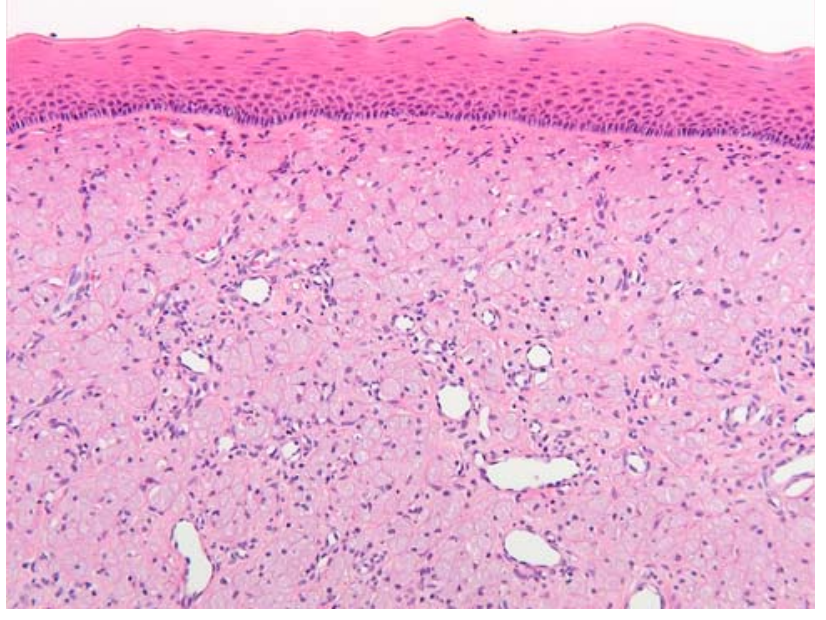

Fig. 2 Case 2, characteristic histology

congenital epulis. Follow-up after 1 month showed normalised feeding and no recurrence.

Case 5 is a female preterm infant born at a gestational age of 32 weeks. Immediately after birth, a solid, fleshcoloured pedunculated nodule was noted on the right side of the mandible. It measured approximately $10 \mathrm{~mm}$ in diameter. Initially, the lesion did not interfere with respiration or bottle feeding, but after a couple of weeks a blister did occur on top of the mass because of friction during bottle feeding. In addition, inadequate mouth closure during suction resulted in aerophagy. A clinical diagnosis of congenital epulis was suspected. Excision was planned at the age of 6 months. At that time, the lesion showed spontaneous involution, with a remaining diameter of 
Table 1 Profile of the five cases

\begin{tabular}{|c|c|c|c|c|}
\hline $\begin{array}{l}\text { Case } \\
\text { no. }\end{array}$ & Sex & Gestation & Location & Excision \\
\hline 1 & Female & Term & Maxilla & 5 Weeks \\
\hline 2 & Female & Term & Mandible + maxilla & 6 Weeks \\
\hline 3 & Female & Term & Mandible & 4 Weeks \\
\hline 4 & Female & Term & Maxilla & 2 Days \\
\hline 5 & Female & $\begin{array}{l}\text { Preterm } \\
\quad(32 \text { weeks })\end{array}$ & Mandible & Regression \\
\hline
\end{tabular}

$3 \mathrm{~mm}$ and without interfering with feeding. Therefore, surgery was cancelled and further regression was awaited. The parents agreed on this. At the age of one year, total remission was seen and there was no further follow-up.

\section{Discussion}

We described five cases demonstrating the classic characteristics of a congenital epulis (Table 1). Only a few larger series, worldwide, have been described $[5,16]$. This congenital nodule is often pedunculated, flesh-pink coloured, firm with a smooth or lobulated surface and in general solitary. However, multiple lesions may also occur in up to $10 \%$ (as seen in one of the cases) and therefore total inspection of the mouth is recommended [3, 5, 7]. Occurrence is sporadical (no reliable figures of incidence are available) and no familial tendencies have been described $[4,5]$. The cases described were seen in four hospitals in The Netherlands between August 2003 and July 2007. The reported size varies from several millimetres to $9 \mathrm{~cm}$ in diameter. There is a slight predilection for the anterior maxillary alveolar ridge [11]. The tumour may interfere with respiration, feeding (like in case 4) or adequate closure of the mouth. One case of polyhydramnios is reported in literature [2]. Recurrence has not been reported, even after non-radical excision, and malignant transformation did not occur.[5, 11, 16] Involution after birth, as in case 5, has been described in literature, but is rare [13, 14].

Diagnosis of congenital epulis can usually be made on characteristic clinical findings described in this article and should be confirmed histopathologically only in cases of doubt [7]. The main differential diagnosis includes Epstein pearls, granular cell tumour, vascular malformations and neuroectodermal tumours of infancy $[5,8,10,11]$.

The pathogenesis of congenital epulis is still unclear. Several theories have been suggested, including an undifferentiated mesenchymal cell origin, fibroblastic, and myoblastic, histiocytic, odontogenic,[4] neurogenic, endothelial and endocrinologic aetiologies $[1,6,7,9,11]$. Most of the reported cases support a mesenchymal origin, rather than odontogenic [5]. In view of the negative S100 staining, neurogenic origin is less likely [7, 11]. The clinical course suggests a degenerative or reactive, rather than a neoplastic, aetiology $[4,5]$.

Since female preponderance, growth of the tumour ceasing after birth and even spontaneous regression after birth have been reported, the development of the tumour might be influenced by endogenous maternal or foetal hormonal factors during pregnancy [5, 9, 14]. However, estrogen- and progesterone receptors have not been detected. This implicates different pathways for this hormonal influence that remain to be defined [5, 6].

Characteristic histological findings shown by these congenital epulides include large round cells with granular, eosinophilic cytoplasm and small eccentric nuclei and a delicate fibrovascular network separating the cells as seen in Fig. 2. In contrast to the granular cell tumour, no layer of pseudoepitheliomatous hyperplasia of the overlying squamous mucosa is present $[1,4,11,16]$. Immunochemically, S100 protein antigen staining has showed negative in three of the cases (specific for Schwann cells), which excludes a neurogenic aetiology and thereby differentiates between an epulis and a granular cell tumour $[4,7,11]$. The congenital epulis is also negative for $75 \mathrm{kD}$ nerve growth factor receptor, trk gene product and phosphotyrosine positive cells, all confirming a lack of neurogenic origin, in contrast to the granular cell tumour (Table 2). PAS, a marker of glycogen, is often positive in both $[1,7]$.

Prenatal imaging of epulis by ultrasonography or magnetic resonance imaging (MRI) is possible. However, congenital epulis is rarely diagnosed prenatally because it slowly develops during the third trimester. At 20 weeks of gestation, the lesion could be not detected on an ultrasound yet $[6,12]$. None of the cases described were diagnosed prenatally. MRI can be used to determine the depth and localisation of a large lesion, for prenatal planning of
Table 2 Common immunohistochemical tests that differentiate between a congenital epulis and a granular cell tumour

\begin{tabular}{llll}
\hline & & Congenital epulis & Granular cell tumour \\
\hline S 100 protein antigen & Specific for Schwann cells & - & + \\
Periodic acid-Schiff staining & Identification of glycogen & \pm & + \\
The $75 \mathrm{kD}$ nerve growth factor & Neurogenic origin & - & + \\
Trk gene product & Neurogenic origin & - & + \\
Phosphotyrosine & Neurogenic origin & - & + \\
\hline
\end{tabular}


delivery method and intervention. This might facilitate parental acceptance and a better mother-infant relationship, since they can prepare for the sight of the lesion and the eventual interventions after birth [10, 15].

Treatment consists of simple conservative excision under general or local anaesthesia, [2] only when major feeding or obstructive respiratory problems are present or a pathological confirmation is looked for [7]. Otherwise, a wait-and-see regimen can be followed since spontaneous involution can occur like in case 5. By "watchful waiting" unnecessary surgery can be prevented [9]. Wide, radical excision is not recommended because of possible damage to the future development of the dentition $[11,12]$.

\section{References}

1. Bilen BT, Alaybeyoglu N, Arslan A, Turkmen E, Aslan S, Celik M (2004) Obstructive congenital gingival granular cell tumour. Int J Pediatr Otorhinolaryngol 68:1567-1571. doi:10.1016/ j.ijporl.2004.07.007

2. Canavan-Holliday KS, Lawson RA (2004) Anaesthetic management of the newborn with multiple congenital epulides. $\mathrm{Br} \mathrm{J}$ Anaesth 93:742-744. doi:10.1093/bja/aeh255

3. Fister P, Volavsek M, Novosel SM, Jazbec J (2007) A newborn baby with a tumor protruding from the mouth. Diagnosis: congenital gingival granular cell tumor. Acta Dermatovenerol Alp Panonica Adriat 16:128-130

4. Godra A, D'Cruz CA, Labat MF, Isaacson G (2004) Pathologic quiz case: a newborn with a midline buccal mucosa mass, congenital gingival granular cell tumor (congenital epulis). Arch Pathol Lab Med 128:585-586

5. Lack EE, Worsham GF, Callihan MD, Crawford BE, Vawter GF (1981) Gingival granular cell tumors of the newborn (congenital “epulis"): a clinical and pathologic study of 21 patients. Am J Surg Pathol 5:37-46

6. Lapid O, Shaco-Levy R, Krieger Y, Kachko L, Sagi A (2001) Congenital epulis. Pediatrics 107:E22. doi:10.1542/peds.107.2.e22

7. Loyola AM, Gatti AF, Pinto DS Jr, Mesquita RA (1997) Alveolar and extra-alveolar granular cell lesions of the newborn: report of case and review of literature. Oral Surg Oral Med Oral Pathol Oral Radiol Endod 84:668-671. doi:10.1016/S1079-2104(97) 90370-X

8. McGuire TP, Gomes PP, Freilich MM, Sandor GK (2006) Congenital epulis: a surprise in the neonate. J Can Dent Assoc 72:747-750

9. Merrett SJ, Crawford PJ (2003) Congenital epulis of the newborn: a case report. Int J Paediatr Dent 13:127-129. doi:10.1046/ j.1365-263X.2003.00435.x

10. Messina M, Severi FM, Buonocore G, Molinaro F, Amato G, Petraglia F (2006) Prenatal diagnosis and multidisciplinary approach to the congenital gingival granular cell tumor. J Pediatr Surg 41:E35-E38. doi:10.1016/j.jpedsurg.2006.07.003

11. Olson JL, Marcus JR, Zuker RM (2005) Congenital epulis. J Craniofac Surg 16:161-164. doi:10.1097/00001665-20050100000033

12. Parmigiani S, Giordano G, Fellegara G, Brevi B, Magnani C (2004) A rare case of multiple congenital epulis. J Matern Fetal Neonatal Med 16(Suppl 2):55-58. doi:10.1080/1476705041000 1727224

13. Reinshagen K, Wessel LM, Roth H, Waag KL (2002) Congenital epulis: a rare diagnosis in paediatric surgery. Eur J Pediatr Surg 12:124-126. doi:10.1055/s-2002-30165

14. Sakai VT, Oliveira TM, Silva TC, Moretti AB, Santos CF, Machado MA (2007) Complete spontaneous regression of congenital epulis in a baby by 8 months of age. Int J Paediatr Dent 17:309-312. doi:10.1111/j.1365-263X.2006.00795.x

15. Silva GC, Vieira TC, Vieira JC, Martins CR, Silva EC (2007) Congenital granular cell tumor (congenital epulis): a lesion of multidisciplinary interest. Med Oral Patol Oral Cir Bucal 12:E428-E430

16. Zuker RM, Buenechea R (1993) Congenital epulis: review of the literature and case report. J Oral Maxillofac Surg 51:1040-1043 